\title{
Economic Pressure and Self-Efficacy as Independent Predictors of Academic Grades and Career Indecision for Southern European Middle School Students: A Confirming Study
}

\author{
Antonio Citarella ${ }^{1 *}$, Juan José Maldonado Briegas ${ }^{2}$, Ana Isabel Sánchez Iglesias ${ }^{3}$ and \\ Florencio Vicente Castro ${ }^{1}$
}

${ }^{1}$ Association of Educational and Evolutionary Psychology for Childhood, Youth, Elderly and Disabled People (INFAD) Researcher, Urb. Universitaria, Badajoz, Spain, ${ }^{2}$ Department of Economy, Extremadura University, Badajoz, Spain, ${ }^{3}$ Hospital del Rey, Burgos University, Burgos, Spain

OPEN ACCESS

Edited by:

Monica Pellerone,

Kore University of Enna, Italy

Reviewed by:

Judit García-Martín,

University of Salamanca, Spain

Martín-Lobo Pilar

Universidad Internacional De La

Rioja, Spain

*Correspondence:

Antonio Citarella

antocita_1978@libero.it

Specialty section:

This article was submitted to

Educational Psychology,

a section of the journal

Frontiers in Education

Received: 06 May 2020 Accepted: 14 September 2020

Published: 23 October 2020

Citation:

Citarella A, Maldonado Briegas JJ,

Sánchez Iglesias Al and Vicente

Castro F (2020) Economic Pressure

and Self-Efficacy as Independent

Predictors of Academic Grades and

Career Indecision for Southern

European Middle School Students: A

Confirming Study.

Front. Educ. 5:559465.

doi: 10.3389/feduc.2020.559465
Using data from the same sample of previous Citarella's (2018) study, this paper aims to confirm the independent role playing by economic pressure due to Great Recession and self-efficacy in determining educational outcomes for middle school students in Southern Italy context. Additionally, the role of mastery goal orientation was tested for this study. Three basic moderation model were developed using Amos (21) and Process (13.4) for SPSS software to test (1) the moderated effect of self-efficacy in the relationship between economic pressure and outcomes; (2) the interaction between self-efficacy and mastery goal orientation in predicting outcomes; (3) the moderated effect played by self-efficacy plus mastery goal orientation in the relationship between economic pressure and outcomes. Results showed that self-efficacy does not moderated the predicting effect of economic pressure on grades and career indecision. Mastery goal orientation positively interact with self-efficacy in predicting outcomes but the moderated effect of the two added integrated constructs was not significantly. Hence, the independent role of economic factors and agency was confirmed by this study.

Keywords: economic pressure, self-efficacy, mastery goal orientation, academic grades, career indecision

\section{INTRODUCTION}

Educational outcomes outline most of job trajectories and positive life adjustment for youth in the contemporary European knowledge society. Although the skills which employers require are often not encountered by youths' educational outcomes generally learned in school systems, high achievers remain advantaged in getting more secure and well-paid job (Mourshed et al., 2014). However, for socio-economically disadvantaged students the opportunity to achieve high skill are lower whilst compared to peer with more economic family resources in OCED countries (De Witte and Tomini, 2017), and the Great Recession that strongly hit European economies in the last decade has exacerbated this situation (Wilska, 2018). During recession students' educational expectations are generally lower on average and higher dependent to family background reinforcing 
social inequality in the distribution of them (Salazar et al., 2019). In addition, in a recent study, Sortheix et al. (2019) showed how global financial crisis produced changes in young European's values increasing self-protection/anxiety control motivations expressed in terms of security and tradition and decreasing growth/self-expansion motivations like hedonism, self-direction, and stimulation. Therefore, in times of crisis youths perceive insecurity and uncertainty about their future educational and career perspectives. Due to the terrifying global impact of current Covid-19 pandemic a new devastating economic recession is expected for the next few years. Social distancing determined working reduction of sectors (e.g., non-food retail, hospitality, travel) where traditionally are employed nongraduates upon leaving education (Henehan, 2020) Therefore, gaps in employment between high and low educated youths will be dramatically increased. Countries which still shaken by the previous crisis (e.g., Italy) that are likely to suffer even more heavily and will have to impose huge sacrifices on their people. In this worrying scenario, inequality in education opportunity and outcomes, youths' disaffection toward knowledge, competence, and effort may further become more evident among different European context. Additionally, if inequality is consistently between-countries related also within-country strongly regional disparities exist in opportunity for youths' education and consequently school-work transition. Quintano et al. (2018) found that students with low educational level and who live in Southern Italy and Isles-where economic rate of poverty and social exclusion is historically and currently high-have significantly more probability to become NEETs if compared with students living in Northern and Central regions of Italy. This negative trend raises for female and immigrant students in a hierarchical inequality seeing weakest individuals most penalized by socio-economic and territorial disadvantage further worsened by economic crisis. Similarly, Salvà-Mut et al. (2018) highlighted the relationship between low educational level, bad economic situation and being NEETs in a sample of youths living in Balearic Islands (Spain) strongly hit by economic crisis. Since NEETs represent the mostly prickly problem for European society, especially for Southern Europe, understanding its relationship with educational outcomes and economic variables become a topic of growing interest as mentioned above. In addition, more attention should be paid to investigate the effect of economic crisis on educational outcomes for early adolescent in Southern European context, because the high vulnerability of these youths to "family stress" due to financial strains (Conger and Elder, 1994). In this regard, in his cross-sectional study, Citarella (2018) analyzed the pathway of influence of exposure to economic crisis on academic grades, career indecision and positive future expectations in a sample of middle school students living in Sicily (Southern Italy). Additionally, the study explored the hypothetical mediational role of self-efficacy in the relationship between economic pressure and outcomes. Therefore, we can note that different levels of systems (societal and individual) according with social ecological perspective (Bronfenbrenner, 1979) were inserted in the conceptual model in order to explore their interrelationships. Results showed a significantly negative impact of economic crisis on academic grades and career decidedness with no significant path of influences on positive future expectations. A strong positive influence showed academic self-efficacy on academic grades, career decidedness, and positive future expectations. However, academic self-efficacy does not mediate the relationships between economic crisis and educational outcomes describing an independent predictive role of the two different levels (societal level and individual level) constructs on educational outcomes.

Using data from the same sample of 500 middle school students this study aims to deep the work mentioned above in order to confirm or reinterpreting the effect (independent or related) of economic downturn and individual academic agency on educational outcomes. In order to achieve a totally exhaustive explanation of this, moderation tests were performed to understand if self-efficacy influence the strength of economic pressure impact on academic grades and career indecision. In addition, for this study, researchers added a new variable, namely mastery goal orientation, excluded in the previous one, with the purpose of analyzing its potentially strengthener effect in promoting personal agency. This deeper further study is justified by the following main question:

Can motivational factors uniquely determine educational outcomes also for students with stressful family economic background or they must be treated as independent correlates?

Answer to this question may have several implications for interventions aimed to improve educational skills in contemporary European society.

Indeed, if motivational factors (e.g., self-efficacy) uniquely affect educational performance even for disadvantaged students, then policies should be focused on strengthening of these individual level factors with teaching playing a prominent role. In this regard, Zuffianò et al. (2013) showed that self-regulated learning played a unique role in predicting academic grades beyond intelligence, personality traits, and socioeconomic status in a sample of Italian students. On the other hand, if the motivational and family socio-economic factors act independently in determining educational outcomes then policies need to move toward a more integrated helpful interventions with supportive actions (included income support) and parental involvement playing a crucial role au pairs of teaching and other specific learning interventions. Supporting this, Chiu and Xihua (2008) in their cross-cultural study, found both motivational factors and family factors (including SES) strongly affected mathematic PISA performances but without relationships each other.

The need of deeper understanding of the role of family economic factors on educational outcomes may be supported also seeing mixed findings of recent research that have focused on the effects of financial strains (e.g., parental job loss, unemployment, income shocks) which can be properly relates to the uncertainty and flexibility of nowadays labor-market and to the last economic crisis. For instance, Mörk et al. (2019) found that parental job loss did not negatively affect schooling outcomes of large sample of Swedish students. In US, the deleterious impact of Great Recession on children educational outcomes was found significant especially in districts where resources for teachers and schooling were reduced as 
consequence of the crisis (Shores and Steinberg, 2017). Analyzing the effects of income shocks due to economic crisis on children educational outcomes in Ireland, McGovern and Rokicki (2018) found a little evidence that temporary shocks income affects educational outcomes in the short run. Finally, the study of Lindemann and Gangl (2019) on intergenerational effect of parental unemployment on educational trajectories of youths, showed that also in Germany-where both low income and high income students have the same learning opportunityparental unemployment affects educational outcomes because of psychological factors related to economic insecurity, namely intra-family well-being and students' choices and aspirations toward fewer risks career trajectories.

The literature's findings show that the impact of economic pressure on educational outcomes is a complex phenomenon and it may vary consistently across different cultural context, including within Western country. In this regard, building on previous Citarella's (2018) study, our effort has been aimed to exhaustively address how economic crisis affected educational trajectories for students living in Southern Italy context where the long wave of its effect is far to be over. To this purpose the following three hypothesis were evaluated:

- H1: "Academic self-efficacy does not moderate the significant effect of adolescents' economic crisis exposure on academic grades and career indecision;"

- H2: "Academic self-efficacy and mastery goal orientation significantly interact in predicting academic grades and career indecision;"

- H3: "The combined variable self-efficacy/mastery goal orientation does not moderate the relationship between adolescents' economic crisis exposure, academic grades and career indecision."

\section{METHODS}

\section{Participants and Procedure}

The sample was composed by 500 youths from four middle schools (241 boys and 259 girls; $M$ age $=12.36$ ) situated in Sicily (Italy). All students were enrolled in the seventh and eighth grade which represent a transition stage for youth as they must take the important educational choice for the subsequent high school (high school preparing for tertiary education or technical or vocational high school) after performing a final institutional exam. Data were collected at the end of 2015 and starting of 2016 using self-administered questionnaires in home setting with parental consent. Schools were chosen excluding extreme level of socioeconomic indicators (neither too high nor too low) in order to better represent a real picture for the impact of economic crisis in middle class. Additionally, selected schools are located both in urban and rural area.

\section{Instruments}

\section{Adolescents' Exposure to Economic Crisis}

Adolescents' perceptions of financial hardships were assessed by constructing an ad hoc scale that included indicators of the respondent's sense that the family is experiencing economic difficulties. Other indices also evaluated direct experiences of deprivation by the adolescents and their worries for personal academic and work future attainments. Items samples include the following: Did your family have to reduce food spending?; Has your pocket-money been reduced in recent years?; Are you afraid of not getting a job when you're an adult? A five-point Likert was used ranging to 1 (Not at all), 3 (Somewhat), and 5 (Very). To validate the scale a Principal component factor analysis was performed and results revealed a one-factor structure with factorloading values ranging from 0.50 to 0.81 . The internal reliability of the scale was very good, with a coefficient alpha of 0.91 .

\section{Academic Self-Efficacy}

The Children's Perceived Self-Efficacy Scales (CPSE) (Pastorelli et al., 2001) was used to assess academic self-efficacy. The 17 items of the instrument measure the self-efficacy perceptions in learning of a range of school subjects, the self-regulation of motivation, and the organization and planning skills of the various academic tasks on a five-point Likert scale ranging from 1 (Totally Unable) to 5 (Totally Able). One item was not used in the study as it was considered unsuitable for middle school students in these specific school contexts. For this study, Principal component factor analysis revealed a one-factor structure with factor-loading values ranging from 0.51 to 0.78 , and a good reliability was found with a coefficient alpha of 0.90 .

\section{Mastery Goal Orientation}

The Mastery Goal Orientation Revised subscale (Midgley et al., 2000) was used to assess mastery goal orientation. The scale is composed by five items measuring the construct on a five-point Likert ranging to 1 (Not all true) 3 (Somewhat true) 5 (Very true). Examples of items are the following: "One of my goals in class is to learn as much as I can" or "It's important to me that I improve my skills this year." For this study, Principal component factor analysis revealed a one-factor structure with factor-loading values ranging from 0.75 to 0.83 , and a good reliability was found with a coefficient alpha of 0.84 .

\section{Career Indecision}

The Ideas and Attitudes on Academic-Career Future (IAACF) scale (Soresi and Nota, 2001) was used to assess career indecision. With a five-point scale ranging from 1 (Does not describe me at all) to 5 (Describes me very well), the instrument measures how confident youths are with regard to their academic professional future. The internal reliability of the scale was good with a coefficient alpha of 0.89 .

\section{Academic Grades}

A seven-point scale with values ranging from 4.0 to 10.0 was used to assess academic grades. The scores were self-reported by students.

\section{RESULTS}

Table 1 shows descriptive statistics and intercorrelations between variables. Adolescents' economic crisis exposure relates significantly and negatively with academic grades while a 
TABLE 1 | Descriptive statistics and intercorrelations.

\begin{tabular}{lccccc}
\hline Variable & $\mathbf{1}$ & $\mathbf{2}$ & $\mathbf{3}$ & $\mathbf{4}$ & $\mathbf{5}$ \\
\hline 1. AECE & - & & & & \\
2. CPSE & -0.02 & - & & & \\
3. MGO & 0.06 & $0.57^{\star *}$ & - & - & \\
4. AG & $-0.29^{\star \star}$ & $0.48^{\star \star}$ & $0.26^{\star \star}$ & $-0.30^{\star *}$ & - \\
5. IAACF & $0.23^{\star *}$ & $-0.22^{\star *}$ & $-0.17^{\star *}$ & 7.05 & 2.31 \\
$M$ & 2.63 & 3.50 & 3.84 & 1.23 & 1.34 \\
$S D$ & 1.27 & 1.12 & 0.815 & & \\
\hline
\end{tabular}

AECE, Adolescents' economic crisis exposure; CPSE, Children's perceived self -efficacy; MGO, Mastery goal orientation; AG, Academic grades; IAACF, Ideas and attitudes on academic-career future.

${ }^{* \star} p<0.01$.

significant positive correlation was found with career indecision. No significant relationships were found between adolescents' economic crisis exposure and academic self-efficacy and mastery goal orientation. Results indicate significant positive correlation with academic grades both for academic self-efficacy and mastery goal orientation. Self-efficacy shows also negative significant relationships with career indecision while no significance was found with career indecision and mastery goal orientation. Finally, significantly negative relationship was found for academic grades and career indecision.

In order to verify a significant moderating effect of academic self-efficacy on the path between adolescents' economic crisis exposure and both academic grades and career indecision, two simple model moderation were performed using Amos software 21. In model $1 \mathrm{a}$, results show that the interaction variable (adolescents' economic crisis exposure $\mathrm{x}$ academic self-efficacy) felt short of statistical significance $(\beta=0.01 ; C R=0.33$; $p>0.05)$ in predicting academic grades. Instead, significant statistical significance in the direct paths with economic crisis exposure predicting worse $(\beta=-0.29$; $C R=-7.77 ; p<0.001)$ academic grades and reversely self-efficacy predicting better ones $(\beta=4.6 ; C R=12.2 ; p<0.001)$. However, self-efficacy does not moderate the negative relationship between economic pressure and academic grades. In model $1 \mathrm{~b}$ the same paths of significance were found. The interaction variable (adolescents' economic crisis exposure $\mathrm{x}$ academic self-efficacy) felt short of statistical significance $(\beta=0.03 ; C R=0.75 ; p>0.05)$ in predicting career indecision. Positive statistical significance was found for the path involving economic pressure and career indecision for adolescents $(\beta=0.22 ; C R=5.1 ; p<0.001)$ while negative significance showed the relationship with self-efficacy and career indecision $(\beta=-0.22 ; C R=-5.1 ; p<0.001)$. Even in this model self-efficacy does not moderate the relationship between economic pressure and outcome. As self-efficacy does not moderate the relationship between economic pressure and outcomes, our first hypothesis was confirmed.

The second our hypothesis was verified testing the interaction between self-efficacy and mastery goal orientation in predicting academic grades and career indecision. Two Hayes's moderation model 1 (Hayes, 2013) was performed using PROCESS MACRO 3.4 (Hayes, 2012) in SPSS 21. For easy comparation with Amos
TABLE 2 | Simply moderation for academic grades.

\begin{tabular}{lcccc}
\hline Variable & $\boldsymbol{\beta}$ & se & $\boldsymbol{t}$ & $\boldsymbol{P}$ \\
\hline Self-efficacy & 0.46 & 0.048 & 9.49 & 0.000 \\
Mastery goal orientation & 0.01 & 0.049 & 0.102 & 0.918 \\
Interaction & 0.08 & 0.037 & 2.23 & 0.026 \\
\hline
\end{tabular}

Interaction $=$ Self-efficacy $\times$ Mastery goal orientation.

TABLE 3 | Slopes for self-efficacy predicting grades at each level of mastery goal orientation.

\begin{tabular}{ccccc}
\hline Mastery goal orientation & Effect & Se & $\mathbf{T}$ & $\boldsymbol{p}$ \\
\hline-1.0000 & 0.379 & 0.063 & 6.02 & 0.000 \\
0000 & 0.461 & 0.049 & 9.49 & 0.000 \\
1.000 & 0.543 & 0.059 & 9.26 & 0.000 \\
\hline
\end{tabular}

results standardized value are used for moderation analysis in Process. Results for the overall model $2 \mathrm{a} F_{(3,496)}=47.42 p<0.001$ $R^{2}=0.23$ show a significant $p$-value and $23 \%$ of variance due to predictors. Table 2 shows that academic grades were significantly predicted by self-efficacy $(\beta=0.46 ; p<0.001)$ while mastery goal orientation does not predict academic grades $(\beta=0.01 ; p>$ $0.05)$. However, the interaction between self-efficacy and mastery goal orientation was significant $(\beta=0.002$; $p<0.05)$ denoting, therefore, a positive moderated effect of mastery goal orientation in the relationship between self-efficacy and outcome.

Results for the conditional effects at three level of mastery goal orientation, namely one standard deviation below the mean (low), at the mean (average), and one standard deviation above the mean (high) indicate a significant predicting value for selfefficacy for all three level of mastery orientation. In Table 3 were showed the slopes for each level of mastery goal orientation.

Although mastery goal orientation does not predict academic grades its interaction with self-efficacy produce a positive moderated effect and acting, hence, in incremental way for the predicting power of self-efficacy on academic grades at all level. This positive interaction effect can be deduced also by the slopes plot depicted in Figure 1.

The second Hayes model was applied to establish if the interaction effect of self-efficacy and mastery goal orientation was significant even in predicting career indecision. Results of the overall model $2 \mathrm{~b} F_{(3,496)}=9.07 ; p<0.001 R^{2}=0.05$ showed a significant $p$-value and $5 \%$ of variance due to predictors. However, while self-efficacy showed a significant predicting effect in the model $\left[\beta=-0.18 ; t_{(496)}=-3.30 ; p<0.01\right]$ mastery goal orientation $\left[\beta=-0.07 ; t_{(496)}=-1.30 ; p>0.05\right]$ and interaction variable $\left[\beta=0.04 ; t_{(496)}=-1.11 ; p>0.05\right]$ felt short of statistical significance. Therefore, diversely for academic grades mastery goal orientation does not moderate the relationship between selfefficacy and career indecision. Therefore, our second hypothesis was confirmed only for academic grades as outcome.

Finally, we proceeded to test the final our hypothesis aimed to verifying the potential moderation role of a combined selfefficacy-mastery orientation variable in the relationships between 


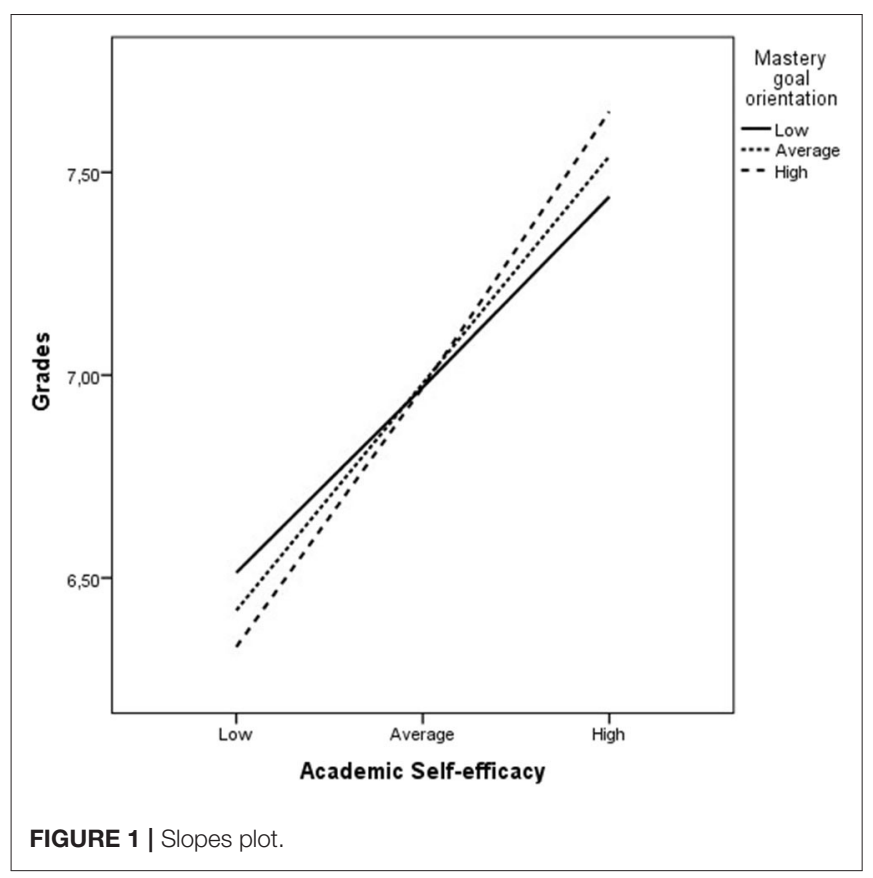

adolescents' economic crisis exposure and outcomes. Since the interaction between self-efficacy and mastery goal orientation was not significant for career indecision, we performed the analysis exclusively for academic grades. A third Hayes model 1 using PROCESS in SPSS 21 was tested. Results of the overall model $F_{(3,496)}=58.63 ; p<0.001 R^{2}=0.26$ showed a significant $p$-value and $26 \%$ of variance due to predictors. However, the interaction variable (self-efficacy/mastery goal orientation $\mathrm{x}$ adolescents' economic crisis exposure) felt short of statistical significance $\left[\beta=0.007 ; t_{(496)}=0.304 ; p>0.05\right]$ showing also this time the independent predicting effect of economic pressure due to the crisis and agentic variables. In fact, economic pressure significantly related to grades $\left[\beta=-0.31 ; t_{(496)}=-7.97\right.$; $p<0.001]$ and the combined self-efficacy plus mastery goal orientation construct also predicts grades $\left[\beta=0.23 ; t_{(496)}=10.8\right.$; $p<0.001]$ but no moderating effect revealed the test. Therefore, our third hypothesis was confirmed.

\section{DISCUSSION}

The relationship between economic factors and education has received wide interest in academic setting due to the role that human and knowledge capital play for economic growth in the contemporary worldwide society (Hanushek, 2016; Hanushek and Woessmann, 2016; Ahsan and Haque, 2017; Grant, 2017; Ali et al., 2018) Likewise, family socioeconomic background constitutes a strongly significant factor in promoting academic progress, especially for youth living in Western country (Lyu et al., 2019). Hence, education for economy and economy for education seems be the bidirectional pathway both for macroeconomics outcomes and individual level of successful outcomes. Nevertheless, the recent global economic crisis has led to raise doubts on the luminous unlimited progress envisaged by globalized society and the neoliberalism economic system, especially in Europe. Despite economic indicators register generally global economic growth country, economic uncertainty and worries continue to persist for many people in several countries joining to other dangerous political and social problems for democratic values such as populism and xenophobia (Erkoc and Ozturk, 2019; Rico and Anduiza, 2019). This confusing situation surely will be aggravated by the unexpected health and economic storm caused by the current Covid-19 pandemic. Italy represent maybe the major evident example of this complex situation whose regional disparities, unequal opportunity and growing discouragement draw a worrying picture, especially for young people. In this regard, Citarella (2018) highlighted the deleterious effect that economic crisis had on educational outcomes of early adolescents in terms of academic grades and career indecision, and without mediating effect of academic self-efficacy. Therefore, if education is the key factor for employment and consequently positive adjustments for youth, the economic pressure hit properly this crucial aspect in a very depressed area of Southern Italy. For this reason, this paper aimed to deep previous Citarella's study in order to confirm the independent role of economic pressure and agentic constructs, namely self-efficacy and mastery goal orientation. Results were consistent with our claims and overall hypotheses. Indeed, selfefficacy does not moderate the negative significance of economic pressure on grades and career decidedness, highlighting that the two variables follow predictive paths without interaction. Conversely, the predictive role of self-efficacy is strengthened by mastery goal orientation in predicting academic grades while no significance was found for career indecision. Finally, the effect of additive variable shaped by the sum of self-efficacy and mastery orientation does not change the independence of relation previously shown by self-efficacy alone. The independent role of economic pressure and agency was, therefore, confirmed by findings of our study. In this regard, several considerations can be made comparing previous evidences showing the influence of family socio-economic background on educational outcomes for adolescents. Analyzing scores of PISA test in science for Italian and Spanish students, Hippe et al. (2018) found several regional disparities among Italian macro regions with family socioeconomic-cultural background playing a generally significant role in determining successful outcomes for students. Indeed, while students living in the richer regions of North-East performed PISA test as other high-level European students, in the Isles (e.g., Sicily) the results were very low. In addition, the socioeconomic -cultural background was found significantly related to PISA scores in all macro-region, but with exception of Isles. This finding for Isles contrasts with generally significant relationships between SES and PISA scores and, importantly, with our results even if it referred only for science subject. With regarding math and reading skills, the socio-economic background was found significantly affecting results of INVALSI (National Institute for the Evaluation of Education Systems) test in primary school and, additionally, with significantly regional significant differences among Northern and Southern Italy (Costanzo and Desimoni, 2017). If social origins explain most of inequality in 
academic outcomes for Italian students (Pensiero et al., 2019), particularly in Southern Italy, regional and disparities should be explained not only by environmental factors but also in terms of efficacy of teaching and management (Argentin et al., 2017). In this regard, Masci et al. (2016) investigated the determinants of academic achievement in reading in Italian context using a multilevel approach. Even for this study, economic social cultural status (ESCS) significantly affects scores in reading and strong differences was observed regarding different geographical areas, with Southern Italy students performing lower scores. However, results for multilevel model highlighted the more important effects at class level compared to school level, additionally implicating a prominent role of teaching in promote academic outcomes. Finally, importantly, "in the South Italy school and class-mean ESCS positively influences the valueadded of school/class, tending to increase the inequalities between more disadvantaged and advantaged students-i.e., for more advantaged students" (Masci et al., 2016, p. 19). It seems clear therefore that socioeconomic background and class related factors like teaching are the prominent determinants of academic achievement for Italian students. In this regard, promoting motivation, self-efficacy, goal-oriented attitude and, hence, encouraging self-regulated learning should be the major challenge for effectiveness of teaching (Zumbrunn et al., 2011). Indeed, our study confirmed the highly significantly effects of self-efficacy and its incremental power through interaction with mastery goal orientation.

Unfortunately, if the relationship with socioeconomic background and academic achievement in Italian context is well-recognized less is known about its relationship with career decidedness and similar correlates. In this regard, Citarella (2018) offered an interesting contribute to stimulate research in this direction overall considering the psychological connection between uncertainty and discouragement that past and future economic crisis could has produced in many European youths. To show this, can be useful conclude our work taking a look to findings of Leach's (2017) qualitative study which suggest interesting reflections on the uncertainty of young people career perspectives in times of economic crisis. Youths interviewed are young public workers which can be imagined as positive and confident in own capacity, in fact "their career narratives reflect the wider, international discourse concerning vocational learning and graduate employability" (p. 4). They enthusiastically believe to improve their career in terms of earning and job satisfaction dreams. Therefore, embarked in a 3-year graduate program. At the end of grade program, the beneficial psychological effects of learning are evident and positive. Unfortunately, on the other hand, Leach (2017) found:

The cruel reality of their experiences is etched into accounts of changes in their employment status, brought about by waves of cuts in public sector funding. Most of all, they express feelings that some fundamental, implicit understandings of a psychological contract between them, the state and their employer is being cruelly violated. These implicit understandings are about notions of mutual obligations of trust, fairness, and social justice in employment practice (p. 9).
An important limitation can be found in this study. Properly, it pertains to the lack of involvement of parental variables in the model. Indeed, positive parenting could alleviate the detrimental effects of economic pressure and promoting agency in students. In a recent study, Hajdu et al. (2019) highlighted the importance of cognitively stimulating home environment in moderating the effect of parental job loss on adolescents' school completion. In their interpretation of results from longitudinal data, authors stressed that families providing cognitively stimulating home environment assign a strong relevance to academic success even in situations of economic hardships. Moreover, Tazouti and Jarlégan (2019) found that the negative impact of SES on elementary students' academic achievement was mediated by parental self-efficacy and parental involvement although principally restricted to mothers. Therefore, parental support may be a crucial factor both in reducing negative effects of family economic distress on youth educational outcomes that in promoting positive learning in them. In this regard, in their qualitative study involving parents and middle school students, Thomas et al. (2019) showed the influence of parents in stimulating autonomy and consequently self-regulated learning in their kids. Consider this, our study suffers of this several limitation since it has included parental variables in the models. Nevertheless, findings could suggest several implications for practices. In fact, the independent pathway of prediction of environmental and agentic factors could be strong despite parental support indicating that interventions should be made following two distinct but integrated directions. First, a strong combined action of welfare, social justice and educational reforms which providing equal learning opportunity for disadvantages youths could be useful and needed. Second, teaching practices should be strongly oriented to encouraging autonomy and self-directed learning in all students also with constructive parental involvement and results of this study further confirm the apical role of selfefficacy and mastery goal orientation in promoting learning. Additionally, Italian curricula should be thought principally considering the urgently need to link skills learned in school system and labor market demands. This is particularly important for all students enrolled at all level (primary and secondary school) since the socioeconomic and geographical gap for disadvantages students begin at early stage as showed by our study. Finally, we can be quite sure that the current health and economic emergency caused be COVID 19 will produce an additionally harder situations for family that already suffer for the long wage of Great Recession spreading inequality in income and educational opportunity. In this regard, the distance learning applied during the lockdown has showed also the digital divide existing in Italy context with students that easily have been adapted to the new form of school learning and students that lacking to devices and competences. Therefore, without an extraordinary financial and educational investment aimed to reduce gap between low and high-income family (especially in terms of technology) a number increasingly growing of Italian youths could be excluded by the fundamental right of education. 


\section{DATA AVAILABILITY STATEMENT}

The raw data supporting the conclusions of this article will be made available by the authors, without undue reservation.

\section{ETHICS STATEMENT}

Ethical review and approval was not required for the study on human participants in accordance with the local legislation and institutional requirements. Written informed consent to participate in this study was provided by the participants' legal guardian/next of kin.

\section{REFERENCES}

Ahsan, H., and Haque, M. E. (2017). Threshold effects of human capital: schooling and economic growth. Econ. Lett. 156, 48-52. doi: 10.1016/j.econlet.2017.04.014

Ali, M., Egbetokun, A., and Memon, M. (2018). Human capital, social capabilities and economic growth. Economies 6:2. doi: 10.3390/economies6010002

Argentin, G., Barbieri, G., Falzetti, P., Pavolini, E., and Ricci, R. (2017). Gaps in educational competencies among northern and southern italian students: the role played by local environments and schools. Soc.Policies 1, 7-28. doi: $10.7389 / 86410$

Bronfenbrenner, U. (1979). The Ecology of Human Development. Cambridge, MA: Harvard University press.

Chiu, M. M., and Xihua, Z. (2008). Family and motivation effects on mathematics achievement: analyses of students in 41 countries. Learn. Instr. 18, 321-336. doi: 10.1016/j.learninstruc.2007.06.003

Citarella, A. (2018). Economic crisis and adolescents' educational outcomes: a case study in southern europe. Int. J. Interdisc. Educ. Stud. 13, 1-16. doi: 10.18848/2327-011X/CGP/v13i04/1-16

Conger, R. D., and Elder, G. H. Jr. (1994). Families in Troubled Times. New York, NY: Aldine de Gruyter.

Costanzo, A., and Desimoni, M. (2017). Beyond the mean estimate: a quantile regression analysis of inequalities in educational outcomes using INVALSI survey data. Large Scale Assess. Educ. 5:14. doi: 10.1186/s40536-017-0048-4

De Witte, K., and Tomini, F. (2017). "Inequality and education: education as a cure for disadvantage," in Handbook of Contemporary Education Economics (Cheltenham, UK: Edward Elgar Publishing), 98-119.

Erkoc, T. E., and Ozturk, A. E. (2019). Examining the Role of Religion, the Economy, and Xenophobia as Challenges to Democracy in the 21st Century. Available online at: https://ssrn.com/abstract=3373023 or doi: 10.2139/ssrn. 3373023

Grant, C. (2017). The Contribution of Education to Economic Growth. K4D Helpdesk Report. Brighton, UK: Brighton Institute of Development Studies.

Hajdu, T., Kertesi, G., and Kézdi, G. (2019). Parental job loss, secondary school completion and home environment. Acta Oeconomica 69, 393-423. doi: 10.1556/032.2019.69.3.4

Hanushek, E. A. (2016). Will more higher education improve economic growth? Oxford Rev. Econ. Policy 32, 538-552. doi: 10.1093/oxrep/grw025

Hanushek, E. A., and Woessmann, L. (2016). Knowledge capital, growth, and the East Asian miracle. Science 351, 344-345. doi: 10.1126/science. aad7796

Hayes, A. F. (2012). PROCESS: A Versatile Computational Tool for Observed Variable Mediation, Moderation, and Conditional Process Modeling [White paper]. Available online at: http://www.afhayes.com/ public/process2012.pdf

Hayes, A. F. (2013). Introduction to Mediation, Moderation, and Conditional Process Analysis: A Regression-Based Approach. New York, NY: Guilford.

Henehan, K. (2020). Class of 2020: Education Leavers in the Current Crisis. Resolution Foundation.

Hippe, R., Jakubowski, M., and Araújo, L. (2018). Regional Inequalities in PISA: the Case of Italy and Spain. Luxembourg: Publications Office of the European Union. EUR 28868.

\section{AUTHOR CONTRIBUTIONS}

$\mathrm{AC}$ and JM realized the literature review and statistical analysis of the article. IS realized the theoretical framing of the article in the research fields of psychology and education. FV realized the final revision of the study. All authors contributed to the article and approved the submitted version.

\section{FUNDING}

This study was funded by INFAD Association.

Leach, T. (2017). 'It seems at the moment my career is dependent on factors outside of my control': reflections on graduates' experiences of employment and career enactment in an era of economic uncertainty and austerity. Br. J. Guid. Counc. 45, 188-198. doi: 10.1080/03069885.2016.1254724

Lindemann, K., and Gangl, M. (2019). The intergenerational effects of unemployment: How parental unemployment affects educational transitions in Germany. Res. Soc. Stratif. Mobil. 62, 1-12. doi: 10.1016/j.rssm.2019.100410

Lyu, M., Li, W., and Xie, Y. (2019). The influences of family background and structural factors on children's academic performances: a cross-country comparative study. Chin. Sociol. 5, 173-192. doi: 10.1177/2057150X19837908

Masci, C., Ieva, F., Agasisti, T., and Paganoni, A. M. (2016). Does class matter more than school? Evidence from a multilevel statistical analysis on Italian junior secondary school students. Soc. Econ. Plann. Sci. 54, 47-57. doi: 10.1016/j.seps.2016.03.001

McGovern, M. E., and Rokicki, S. (2018). The Great Recession, Household Income, and Children's Test Scores (No. 18-05). Centre for Health Research at the Management School (CHaRMS). Available online at: https://EconPapers.repec. org/RePEc:qub:charms:1805

Midgley, C., Maehr, M. L., Hruda, L. Z., Anderman, E., Anderman, L., Freeman, K. E., et al. (2000). Manual for the Patterns of Adaptive Learning Scales (PALS). Ann Arbor, MI: University of Michigan.

Mörk, E., Sjögren, A., and Svaleryd, H. (2019). Parental Job Loss and Child Human Capital in the Short and Long Run: An Analysis of Workplace Closures 19952000, Working Paper, No. 2019:3, Institute for Evaluation of Labour Market and Education Policy (IFAU), Uppsala.

Mourshed, M., Patel, J., and Suder, K. (2014). Education to Employment: Getting Europe's Youth Into Work. Washington, DC: McKinsey Center for Government.

Pastorelli, C., Caprara, G. V., Barbaranelli, C., Rola, J., Rozsa, S., and Bandura, A. (2001). The structure of children's perceived self-efficacy: a cross-national study. Eur. J. Psychol. Assess. 17, 87-97. doi: 10.1027//1015-5759.17.2.87

Pensiero, N., Giancola, O., and Barone, C. (2019). "Socioeconomic inequality and student outcomes in italy," in Socioeconomic Inequality and Student Outcomes. Education Policy \& Social Inequality, Vol 4, eds L.Volante, S. Schnepf, J. Jerrim, and D. Klinger (Singapore: Springer), 81-94.

Quintano, C., Mazzocchi, P., and Rocca, A. (2018). The determinants of Italian NEETs and the effects of the economic crisis. Genus 74:5. doi: 10.1186/s41118-018-0031-0

Rico, G., and Anduiza, E. (2019). Economic correlates of populist attitudes: an analysis of nine European countries in the aftermath of the great recession. Acta Politica 54, 371-397. doi: 10.1057/s41269-017-0068-7

Salazar, L., Cebolla-Boado, H., and Radl, J. (2019). Educational expectations in the great recession: has the impact of family background become stronger?. Socio Econ. Rev. 18, 465-491. doi: 10.1093/ser/mwy046

Salvà-Mut, F., Tugores-Ques, M., and Quintana-Murci, E. (2018). NEETs in Spain: an analysis in a context of economic crisis. Int. J. Lifelong Educ. 37, 168-183. doi: 10.1080/02601370.2017.1382016

Shores, K., and Steinberg, M. (2017). The Impact of the Great Recession on Student Achievement: Evidence From Population Data. Available online at: https://ssrn. com/abstract $=3026151 \sim$

Soresi, S., and Nota, L. (2001). "Introduzione e Interessi e Valori. Optimist, portfolio per l'orientamento [Introduction, and Interest and Values. Optimist, 
a Vocational Portfolio]. Florence: ITER-Institute for Training Educational and Research.

Sortheix, F. M., Parker, P. D., Lechner, C. M., and Schwartz, S. H. (2019). Changes in young Europeans' values during the global financial crisis. Soc. Psychol. Personal. Sci. 10, 15-25. doi: 10.1177/1948550617732610

Tazouti, Y., and Jarlégan, A. (2019). The mediating effects of parental selfefficacy and parental involvement on the link between family socioeconomic status and children's academic achievement. J. Fam. Stud. 25, 250-266. doi: 10.1080/13229400.2016.1241185

Thomas, V., Muls, J., De Backer, F., and Lombaerts, K. (2019). Exploring self-regulated learning during middle school: views of parents and students on parents' educational support at home. J. Fam. Stud. 1-19. doi: 10.1080/13229400.2018.1562359

Wilska, T.-A. (2018). Book review: Student Lives in Crisis: Deepening Inequality in the Times of Austerity. Available online at: https://www.tcrecord.org/content. asp? contentid $=22252$

Zuffianò, A., Alessandri, G., Gerbino, M., Kanacri, B. P. L., Di Giunta, L., Milioni, M., et al. (2013). Academic achievement: the unique contribution of self-efficacy beliefs in self-regulated learning beyond intelligence, personality traits, and self-esteem. Learn. Individ. Differ. 23, 158-162. doi: 10.1016/j.lindif.2012.07.010

Zumbrunn, S., Tadlock, J., and Roberts, E. D. (2011). Encouraging Self-Regulated Learning in the Classroom: A Review of the Literature. Richmond, VA: Metropolitan Educational Research Consortium (MERC).

Conflict of Interest: The authors declare that the research was conducted in the absence of any commercial or financial relationships that could be construed as a potential conflict of interest.

Copyright (c) 2020 Citarella, Maldonado Briegas, Sánchez Iglesias and Vicente Castro. This is an open-access article distributed under the terms of the Creative Commons Attribution License (CC BY). The use, distribution or reproduction in other forums is permitted, provided the original author(s) and the copyright owner(s) are credited and that the original publication in this journal is cited, in accordance with accepted academic practice. No use, distribution or reproduction is permitted which does not comply with these terms. 